\title{
ENTREVISTA COM O POETA, ESCRITOR DE PROSA DE FICCÃO, ENSAISTA E PROFESSOR HeLDER MACEDO
}

http://dx.doi.org/10.11606/issn.2175-3180.v13i24p60-66*

Por Ana Cristina Joaquim ${ }^{\mathrm{I}}$ Rui Daniel Nascimento Sousa II

ANA CRISTINA JOAQUIM: Em 2015, você publicou em Portugal, pela Editora Presença, um longo poema intitulado Romance (edição brasileira pela Lumme, 2016), cujo diálogo com a obra de Bernardim Ribeiro é insistentemente ressaltado. Como crítico, em 1977, publicou Do Significado Oculto da Menina e Moça; em 1990, uma edição de Menina e Moça de Bernardim Ribeiro e, em 2008, em parceria com Maurício Matos, a edição das Obras Completas de Bernardim Ribeiro. Tendo em vista essa intersecção entre o poeta e o ensaísta (e considerando-se a consistência de sua larga carreira tanto como acadêmico e ensaísta, quanto como poeta e escritor de prosa de ficção), de que modo você diria que as atividades criativas e acadêmico/investigativas - com modi operandi tão diversos - convivem na sua forma de se relacionar com a tradição literária?

\footnotetext{
* Publicada originalmente na revista Desassossego, v. 8, n. 15, jun/2016:

https://www.revistas.usp.br/desassossego/issue/view/8738

DOI original: http://dx.doi.org/10.11606/issn.2175-3180.v8i15p200-205

I Universidade de São Paulo, São Paulo, Brasil.

II Universidade de Lisboa, Lisboa, Portugal.
} 
HELDER MACEDO: A linguagem literária não é feita apenas de palavras, é também feita com uma tradição pessoalmente assumida por cada escritor. Que passa a fazer parte do imaginário de quem escreve. Não sei se o meu interesse, enquanto ensaísta, por autores como Bernardim Ribeiro (ou Camões, ou Machado de Assis, ou Cesário Verde) partiu da minha leitura da obra deles ou, em sentido inverso, derivou da minha própria escrita literária. Afinal já tinha obra publicada como poeta e já tinha escrito obras de ficção quando me tornei professor universitário. Sou um universitário tardio... Mas creio que as duas coisas vão juntas. Aliás, nos meus romances (e também nos meus poemas mais recentes) tenho integrado ecos deliberados de outros autores. São parte do meu vocabulário criativo. Como se fossem personagens subliminares nos romances, metáforas implícitas nos poemas. Em última análise, eu sou a mesma pessoa que escreve poesia e ficção e que escreve ensaios de análise literária. As metodologias são diferentes e não podem ser confundidas, é só isso. Um ensaísta "poético" é um mau ensaísta. Um romancista "ensaístico" é geralmente um chato. Ser chato é um pecado mortal em literatura. Incluindo a ensaística.

RUI DANIEL NASCIMENTO SOUSA: Comemorámos recentemente o centenário da revista Orpheu, a que se seguem este ano o centenário da morte de Mário de Sá-Carneiro e de outras duas revistas do contexto do modernismo português, prolongando-se esta pluralidade de efemérides em 1917 com o centenário de Portugal Futurista. O Helder Macedo pertence a uma geração que conviveu directamente com as primeiras edições completas da Obra de Fernando Pessoa, em 1942, assim como com as publicações de obras de Mário de Sá-Carneiro (Indícios de Oiro, em 1937, e a correspondência com Pessoa, em 1958-1959) e da versão integral da almadiana Cena do Ódio, em 1958. No âmbito do Café Gelo, conviveu directamente com Raul Leal, outra personalidade singular do Orpheu. A seu ver, qual a importância do Orpheu, enquanto grupo e revista, e que impacto teve essa onda de publicações no contexto de encontro poético representado pelo Grupo do Gelo?

HM: O Modernismo do Orpheu foi determinante na nossa formação literária, é claro. E vimos uma clara continuidade entre a geração do Orpheu, os surrealistas e nós próprios, os jovens que recusávamos a literatura 
"oficial" e procurávamos novos caminhos. Aliás, não apenas (ou sobretudo) literários, mas também éticos e políticos. Acho que todos concordámos com o então ainda pouco conhecido Eduardo Lourenço quando sugeriu que a presença (em contraste com o Orpheu) tinha representado a contrarrevolução do Modernismo. A Engomadeira, do Almada, é porventura a obra prima da prosa surrealista portuguesa... antes de haver surrealismo com esse nome em Portugal. Às vezes, cruelmente, telefonávamos para casa do Júlio Dantas depois da meia-noite a gritar “Morra o Dantas, morra, Pim!" O velho Raul Leal e o então ainda jovem Mário Cesariny foram recebidos no Gelo como os nossos naturais antecessores. E também, dos poetas da presença, o dissidente e geralmente inapreciado Edmundo de Bettencourt (o autor dos admiráveis Poemas Surdos, ao tempo ainda inéditos) foi para nós uma referência exemplar. $\mathrm{O}$ Herberto Helder e eu íamos visitá-lo diariamente no Café Restauração, no lado oposto da rua atrás do Gelo.

RDNS: Costumam referir-se regularmente o marcado e sugestivo teor autobiográfico assumido por muitas das suas obras, constituindo estas recriações tanto de uma experiência pessoal como da memória e vivência de uma época particularmente rica. Em que medida a introdução de uma personagem como Luís Garcia de Medeiros, no contexto de Partes de África, espelha esse diálogo e mescla entre a memória autobiográfica, a experiência de um contexto colectivo e a subtil intromissão de um tratamento ficcional desses materiais?

HM: Todos os romances e, não menos, toda a poesia têm um teor autobiográfico. Os romancistas escrevem-se a si próprios nas suas personagens, mesmo quando se diferenciam delas. Ou talvez mesmo para se poderem diferenciar delas, para não serem quem não são ou querem não ser. Usar-me como personagem nos meus romances é apenas (ou sobretudo) uma técnica literária de verossimilhança. Tornando explícito o que geralmente está implícito nos romances tradicionais. Mas o "eu" usado numa ficção literária não é o mesmo "eu" que a escreve. Ao contracenar, num romance, com uma personagem fictícia torna-se numa personagem tão fictícia como as outras. Mas, ao mesmo tempo, dá-lhes uma aparente credibilidade "factual". Em vários dos meus romances em que me uso como personagem identifico-me mais com uma das outras personagens do que 
com essa que "factualmente" parece coincidir comigo. É o caso de Pedro e Paula e, sobretudo, de Vícios e Virtudes onde o eu que, enquanto personagem, coincide biograficamente comigo, é manipulado pela fictícia personagem feminina de Joana. Que toma conta do livro. Mas, é claro, essa Joana é uma personagem criada por mim, enquanto autor implícito tanto dela, quanto desse aparente autor que biograficamente coincide comigo. Além de que, em termos da chamada criação literária, é difícil distinguir entre a imaginação e a memória. Tanto a imaginação quanto a memória são representações daquilo que não há: daquilo que já aconteceu e, portanto, não está a acontecer agora, e daquilo que não está a acontecer agora mas poderia ter acontecido ou vir a acontecer ou nem uma coisa nem outra. $\mathrm{O}$ personagem do Luís Garcia de Medeiros, no meu romance Partes de África, é simultaneamente uma memória fictícia e uma invenção factual. E é também uma saudação cúmplice aos meus coautores dele, o Herberto Helder e o José Sebag e todos os do Gelo. Somos uma geração de suicidas, alguns dos quais sobrevivemos a nós próprios... Como o Luís Garcia de Medeiros, que é todos nós e nenhum denós.

$A C J$ : Há alguma frequência no diálogo que você mantém com tradições esotéricas, sobrenaturais e religiosas, tanto no seu trabalho como crítico (Do Significado Oculto da Menina e Moça, Camões e a Viagem Iniciática), quanto no seu trabalho criativo (para mencionar um exemplo de peso, faço menção aos poemas inscritos em Os trabalhos de Maria e o Lamento de José). Também alguns surrealistas (como é o caso de Mário Cesariny com a Cabala) e Herberto Helder com a alquimia, com quem você conviveu nos encontros do Café Gelo, têm essa questão como recorrente na produção poética. Partindo da sua experiência particular, o que você diria sobre a retomada do interesse pelo misticismo no século XX?

HM: Não tenho a mais pequena sombra de fé religiosa. O "Barbas", como o meu amigo e camarada do Gelo, João Rodrigues, designava deus, é uma invenção humana. Que foi talvez uma necessidade para explicar o inexplicado. Deus, todos os deuses e todas as religiões, são a sintaxe do inexplicado. Que, ao longo dos séculos, se traduziu em arte, em poesia, no misticismo. O que a mim me interessa não é a fé religiosa, é a sintaxe do misticismo. Que é uma capacidade humana e não uma manifestação divina. Porque aquilo que não existe, o deus ou os desuses que não há, não se 
manifestam, são humanamente manifestados. Disciplinas esotéricas comoa cabala ou a alquimia constituíram vocabulários das aspirações humanas. Da criatividade humana. Gosto sobretudo na cabala da ideia de que o alfabeto constitui o nome secreto de deus. E, na alquimia, que a "matéria simples" pode adquirir "forma", que é a busca à forma, como disse Camões. $\mathrm{O}$ significado oculto da Menina e Moça é, em última análise, a expressão humana do divino. A viagem iniciática de Camões foi a transformação da demanda do divino na demanda do humano. Da busca da felicidade na vida e não na morte. Os meus Trabalhos de Maria são poemas da materialidade da carne e não da imaterialidade do espírito. São a voz de uma mulher a ensinar os homens que a carne gera o espírito, que as almas sangram. Creio que o interesse do Herberto Helder na alquimia, ou do Manuel de Castro nas religiões orientais também não derivava de crenças religiosas. Acho que eles, como eu, também visavam significar a transcendência em imanência. E que, tal como eu, visavam celebrar o feminino, do qual todos viemos, homens e mulheres. Um dos mais belos poemas do Herberto é sobre a menstruação. Por outro lado, julgo que o interesse do Cesariny na cabala era sobretudo pelos seus aspectos linguísticos, pelas permutações entre letras e entre palavras que, formalmente, anteciparam os jogos literários do surrealismo. Quanto ao actual interesse pelo misticismo, no seu sentido de fé religiosa e de desejo de salvação da alma depois da morte da carne, isso parece-me ser outro assunto. É uma regressão ao que é menos interessante e, para mim, menos importante no misticismo: o desejo de "salvação" individual. O amor gorduroso da vida, como disse o Fernando Pessoa aliás para significar o oposto do que estou a dizer. Mas o Pessoa teria gostado de ter a fé religiosa que não tinha. Acho, no entanto, que todos nós concordaríamos que, por exemplo, uma representação pictórica do divino - por exemplo, o Ecce Homo que está no Museu de Arte Antiga em Lisboa - é mais verdadeira, e por isso mais bela, do que a divindade representada.

$A C J$ : Sobre a sua produção crítico-ensaística nota-se, além da grande extensão quantitativa, uma diversidade de épocas marcante, pois que se dedicou a Bernardim Ribeiro e Camões, mas também a Cesário Verde (ainda mais marcante, se se considera a sua atuação criativa, que o situa com força tremenda nos acontecimentos literários relevantes destes séculos XX e XXI). De que maneira você descreveria a sua trajetória como ensaísta, 
tendo em vista a abrangência histórica que caracteriza a sua produção?

HM: A cronologia literária é uma tarefa útil para os arrumadores das almas, os historiadores da literatura. Convém fazê-la para depois se poder relacionar obras, autores e tempos diferentes. O Camões não é menos do meu tempo do que, por exemplo, o Pessoa, e o Pessoa não o é mais do que do que, por exemplo o Bernardim Ribeiro e o Cesário Verde. Ou o Herberto Helder, ou o Manuel de Castro, ou escritores mais novos do que eu, como por exemplo o António Cabrita ou o Paulo José Miranda, para só mencionar esses dois com quem tenho mantido um novo diálogo sempre renovado. No fundo, só escrevo sobre o que me interessa, quer seja como poeta, como romancista ou como ensaísta. E o que me interessa muitas vezes também interessa ou interessou ou vai interessar outros, antes ou depois de mim, que desse modo se tornam meus contemporâneos.

RDNS: Na recente apresentação conjunta das suas mais recentes obras, Romance Resta Ainda a Face, o Helder assinalou a enorme surpresa e prazer de manter diálogos contemporâneos com uma nova geração de poetas, escritores e estudiosos que se começaram a interessar pela sua obra e a darlhe novos sentidos e releituras. Parece-lhe que de algum modo a sua experiência vital, desenvolvida a partir de um olhar à distância sobre a realidade portuguesa, iniciado com um exílio voluntário que respondia a uma outra forma de exílio colectivo intensamente presente em Portugal e prolongando-se com uma cada vez mais reconhecida carreira de escritor, crítico e figura destacada da nossa cultura, ecoa na actual consciência de crise e instabilidade em que vivem os criadores, condenados a novas formas de exílio?

HM: Bom, acho que um escritor - um poeta, um artista - é sempre um exilado, mesmo de onde está ou parece estar. E que, por isso, é um construtor de mundos ou lugares ou tempos alternativos. É sempre necessário fazer uma distinção inicial entre os processos criativos e as obras realizadas. Ou seja, no caso, por exemplo, de um escritor ou de um pintor, entre o fazer de um livro ou de um quadro e a sua publicação numa editora ou exposição numa galeria. Posto isso, o passo seguinte é publicar ou expor. Ou seja, tentar comunicar aquilo que havia sido um processo "exiladamente" solitário numa consequência participantemente 
partilhada. Mas se, nesse segundo momento do processo, que é a recepção do que se pretendeu comunicar, não há o estímulo da partilha, o impulso criativo pode ir diminuindo. É como falar para surdos, ao fim de algum tempo apetece desistir. E, então, o exílio deixa de ser criativo, passa a ser existencial. No que me diz respeito, o facto é que escolhi escrever em português vivendo na Inglaterra. Poderia ter escrito em inglês, a minha carreira universitária é inglesa, mas a minha opção literária foi portuguesa. Dirijo- me, portanto, a quem não está à minha volta. Talvez haja nisso um ganho, pois não me permite confundir o processo criativo com a sua eventual recepção por potenciais ou hipotéticos leitores. Falo para eles e elas, quem quer que sejam ou venham a ser, a partir de mim, e não a partir delas e deles para mim. Se o que tenho a dizer lhes interessar, tanto melhor, mas não é problema meu. Mas, se não lhes interessar, também pode haver uma perda para mim, ser um desincentivo, tornar-se num problema meu. Em todos os meios literários, não é só no português, quem não está presente e envolvido nas politiquices literárias (festivais, prémios, fofocas, jogos de poder, compadrios) tende a ser ignorado ou esquecido. Portanto, se apesar disso, uma nova geração está de facto a interessar-se por aquilo que escrevo e que tenho escrito, fico de facto contente. E sinto-me estimulado. É sinal de que, apesar do meu exílio (ou talvez por causa do exílio?), consegui comunicar o que fui tentando dizer. E que alguma coisa do que fui tentando dizer faz algum sentido para além de mim.

\section{Licença: (9) (1) (\$)}

Concepção e realização da entrevista:

\section{Ana Cristina Joaquim}

Pós-doutoranda na Universidade Estadual de Campinas. Doutora egressa do Programa de PósGraduação em Literatura Portuguesa da Universidade de São Paulo.

Contato:wiquen@gmail.com

(D) : https://orcid.org/0000-0002-7227-0195

Rui Daniel Nascimento Sousa

Doutor em Estudos Literários, variante Literatura Portuguesa, pela Faculdade de Letras de Lisboa.

Contato: ruidnsousa@gmail.com

(iD) : https://orcid.org/0000-0002-2810-0092 